liver and lung. There can be little doubt that these deposits originate in a fibrinous material exuded from the vessels in certain pathological states (congestion, cbronic inflammation, and malnutrition), and forming a dense structure of low
vitality, which tends by its subsequent contraction to constrict and compress the adjacent parts, and so more or less to interfere with the passage of blood through them, and consequently to derange their nutritive and vital operations. The same tendency is evinced in the highex (less avlastic) forms of tuberculous disease. Mliary or gramular fubercles in the lungs, when in considerable numbers and not soon softening, cause a contraction in the substance of the organ, chiefly at the upper part, and a corresponding collapse in this portion of the chest. I have mes with many cases in which a sinking of the infraclavian region has tiken place before any signs of softening have occurred; indeed, this is a very common sign of tubercles which remain long stationary. The still greater amount of pectoral collapse in the alvanced stages of tuberculous lesions, although partly dependent on other causes, is also still in some degree connected with the contraction of cacoplastic deposits in the lungs and pleura. In the peritoneum agglutinated tubercles often cause considerable contraction. I have seen the omentum puckered up by them into a knotty mass.

The microscopic examination of cacoplastic deposits, at different stages of their formation, throws considerable light upon the true nature of this process. When recent the effused matter consists of fibres, with a great quantity of granular, and more or less of amorphous substance, with or without an admixture of cells. At a later period, and after it has contracted, it is much more tough, and it is then found to be more distinctly fibrous, much of the granular and amorphous matter having disappeared. Old contractile adhesions and cicatrices are still denser, and when examined by the microscope are seen to consist of closely interwoven fibres, differing from those of fibro-cartilaginous tissue in being less regular and distinct. Grey or granular tubercles wither, and become more tough or horny ("cornify," Rokitansky), and thus remain quiescent. It appears, therefore, that it is by the partial absorption of the granular and amorphous portion of the deposit, and by the closer approximation of the fibrous or more organised con. stituent, that the condensation takes place. Hence it is that the structure thus contracted is less liable subsequently to the further degeneration to which cacoplastic products are prone. Certain it is, that of different portions of cacoplastic deposit in the lungs and elsewhere, those that are contracted remain unchanged, whilst the rest pass into the aplastic state of opaque and softened tubercle. The contractile process seems, therefore, to raise the deposit to a higber standard, so that, although still inferior in vitahty to the adjoining textures, it gets to be tolerated by them, so to speak. But this very change may seriously injure the textures of organs by contrecting and compressing their vessels, and interfering with their nutrition and other functions; and in this respect it may be compared with the highest, or most animalised variety of degeneration, the fibrous, which has already heen described. It is in this way that the contractile diseases of the liver and kidneys gradually infringe on the circulation and secretion of those organs, and eventually prove fatal. The contraction which takes place near the apices and roots of the lungs in the more limited, and therefore more chronic, varieties of julmonary tuberculous disease, often lays the foundation of emphysema of the organ and habitual asthma.

Having described the less degraded and degenerating form of cacoplastic deposits, it now remains to notice the variety which is of a lower charncter, and which tends to become aplastic. This includes all the commoner forms of tubercle. In the granular, miliary, grey, or drab-coloured tubercles of serous membranes and of the paren byma of organs there is found a dense homogencous solid, closely resembling some of the cacoplastic deposits which have just been described. The resemblauce, even the identity, of these may often be very well traced out in chronic or suhacute arachnitis, peritonitis, anr pleuritis; portions of the affected membrane are covered with diffused masses of semi-npaque demosit, which no one would hesitate to call false membrane, whilst in other parts separate granules of preciscly the same deposit $x$ hibit all the characters of granular or miliary tubercle. In chronic and scrofulous inflammation the matter efinsed is, from the first, less ductile and more consistent, and the grauular cordition consequently more generally prevails, and remitins even in spite of pressure and friction; and it is ainitted that the product of chronic inflammation of the peritoreun and of the arachnoid membrane is always more or less granulitr. In acute inflammation in tuber- culous subjects recent lymph is commonly studded with opaque ranules, which subsequently assume the character of tubercles. But tubercular deposit is not always preceded by inflammation. In many cases tubercles are found so extensively disseminated through different textures, after few or no symptoms of inflammation, that it is quite impossible to regard them otherwise than as the result of moditied textural nutrition.

Miliary tubercles exhibit a considerable variety in size and consistence, according to their age. When recently formed they are plump, and although feeling harder than the surrounding textures, yet they can be crushed with firm pressure between the fingers. But in lapse of time they contract in size, and become tougher, so that no pressure can crush them. This change in the lung is accompanied by a darkening of colour, so that old tubercles are often quite black. This is an indication of the tubercle having become quiescent or obsolete, and having little tendency to degenerate to the yellow state.

Tubercles rarely occur in numbers, or spread much, without exhibiting another change of appearance : they lose their semitransparency, and become of an opaque or dead pale-yellow hue, hke the colour of raw potato or parsnip. This marks the transformation to crude yellow tubercle first described by Laennec, and this is the result of a further degradation or degeneration of the deposit. The few fibres and cells which are to be detected in grey tubercle are no longer distinguishable here; the interstitial hyaline or amorphous solid is greatly diminished, oil-globules appear in its stead, and the mass becomes proportionately less coherent and more granular, and is now, indeed, quite aplastic. Generally the change begins in the centre of the mass, apparently because, there being no permeating vessels, the centre is the part furthest removed from the vivifying influence of the blood. The cornea and other nonvascular textures occasionally become opaque in a similar way, in consequence of deficient supply of sustaining nutriment in the plasma, and may, indeed, entirely lose their organisation. A parallel form of degradation is that observed in the degeneration of fibrous and cellular tissues into granular matter, recently pointed out as resulting from malnutrition. But not only will deficient supply of healthy plasma promote the transformation of tubercle from grey to opraque; an undue flow or accumulation of blood, produced by inflammation or congestion in the neighbourhood, will also accelerate the change, just as the same occurrence hastens the disintegration of ly mph and of compressed textures in suppuration, the conversion of the plastic into aplastic, through the increased warmth and afflux of fluids exalting chemical affinities in a material which has none of that vital power of resistance by which living tissues maintain their integrity.

(To be continued.)

$\mathrm{ON}$

\section{THE MECHANICAL TREATMENT OF ORAL} DEFORMITIES.

\section{By ROBERT RAMSAY amd J. OAKLEY COLES, Esge}

MODERN discoveries and inventions have allowed the dental profession to progress rapidly during the last ten years in this branch of their science. Mechanical appliances for substituting parts which have been left defective by congenital malformation, or for restoring parts which have been carried away by disease, can now be so perfectly replaced artificially that an account of the two following cases may be interesting to surgeons generally, and particularly to those members of the profession whose special practice may have brought them in contact with similar deformities; for, as will be demonstrated as we proceed, the deficiency or loss of substance was so great that surgical treatment of either of them would have been impossible. These cases will, we feel assured, be the more interesting when we say that such or others very similar are far from being uncommon.

There are, however, special as well as characteristic features in both the cases we now have to describe. Both were the result of disease. In one case the loss by ulceration was exclusively confined to the soft palate; while in the other a large portion of the superior maxillary bone was destroyed, the soft palate remaining perfect from being untouched by the ravaging disease so closely adjacent. 
The treatment of these cases was not unwcompanied with peculiar difficulties. In regard to the former they were: (1) the aperture being confined entirely to the soft palate, there was no firm base for receiving and keeping in its place such a delicate instrument as it was necessary to umploy; (2) the degree of elasticity required in that portion of the instrument which would have to cover the edges of this fissure; and (3) the necessity for producing a pertect closure, without at the same time causing any painful irritation by pressure, for this would have induced, in all probability, a return of ulceration, and thereby caused furtter loss of parts. It was not less important for the comfort of the patient than it was for the credit of the operator, that these points should be studionsly and stedfastly kept in view.

The means that were adopted for overcoming these selfevident operative diffeculties may now be briefly related. In the first place, as the professional reader will judge, perfect impressions of the injured parts were neeessary. 'These could not be taken, however, by the usual process adopted by dental surgeons-viz., by the use of wax ; for the force requisite to obtain an impression in this material would hare so distorted the soft palate from its normal or resting form, that any model thus taken would have been altogether untrue, and therefore valueless. The use of plaster of Paris was then the only alternative left. By introducing this substance in a form so liquified that it was of the consistency of thick cream, the pressure required to pass enough of it above the edges of the fissure did not displace the most delicate folds of mucous membrane. In a few moments it was sufficiently set to be withdrawn, and on inspection a model was presented, not with a "dragged" appearance, as a dentist would term an unsatisfactory attempt, but with clear, sharp, and well-defined outlines. Thus a model, which contained an accurate impress both of the dental arch and what remained of the soft palate, was secured. From a drawing of a cast taken from the model, we are enabled to present, in Fig. 1, an exact copy of the upper part of the 2atient's mouth as it was presented to us for treatment.

Fra. 1.

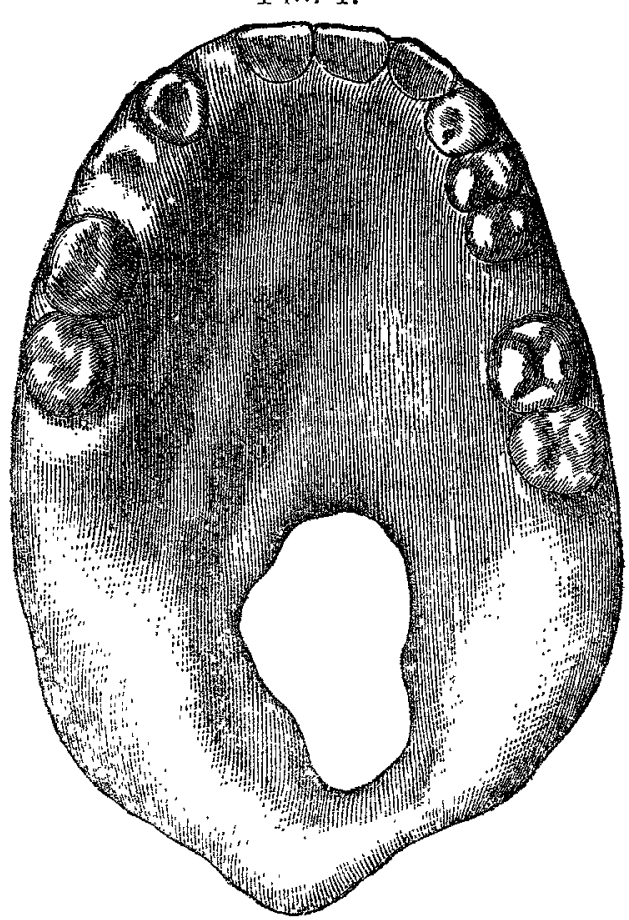

By working to this model, the required moulds were made for receiving the material to be shaped into form. This material was a composition of india rubber prepared for vulcanising: The plug-if we may use so plain a term, with a view to be clearly understood - was necessarily of a most flexible quality of this compound; while the front part of the instrument, which would have to carry the teeth to be replaced, as well as the plug, wras of the usaal ebonite quality employed in dentistry. The supple yet unaltcrable character of the one part, and the rigid, indestructible condition of the other, are suggestive examples in juxta-position for showing the incalculable value of india-rubber, indicating as they do the numerou and efficient uses to which it may be tuined. The following Figares $(2$ and $2 a)$ will show the bearer of the plug and the plug itself in detachedi parts.

The next illustration (Fig. 3) shows the instrument in a complete form for inserting in the mouth. Here we may incidentally remark that, as the elastic portion is made in a

metallic mould, it may be duplicaied in any number; and so easily may this be done that in this instance the patient, who was going to India, was provided with a mould and a small vulcauising apparatus, whereby he was able to construct a new plug when necessary.

FIG. 2.

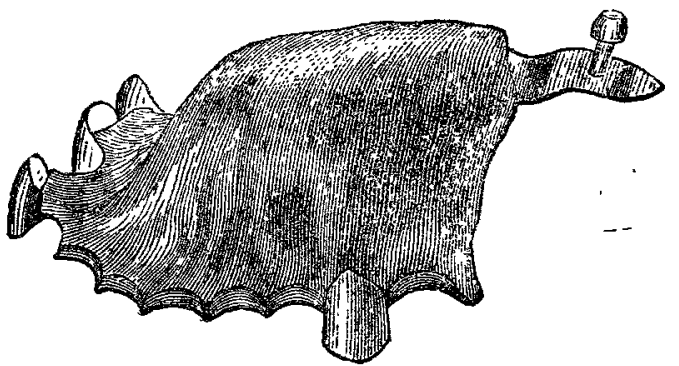

Fra. 3.

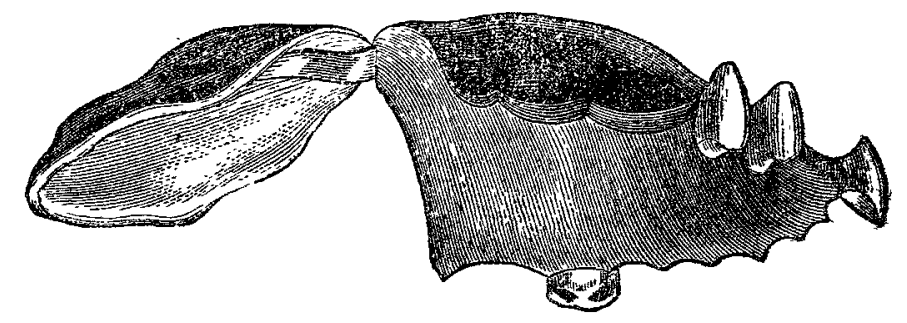

Simple as this instrument may appear when thus presented, we may say it required some weeks' close application to bring it to this degree of perfection. When the moulds were satisfactorily completed, however, the remaining processes were readily accomplished. The hard rubber front piece (Fig. 2) fitted so perfectly that it was kept firmly in its place by the power of suction, at the same time that it pressed the plug (Fig. 2 a) upwards with equal consistency. The whole instrument, when in silu, presented the appearance which is conveyed in Fig. 4.

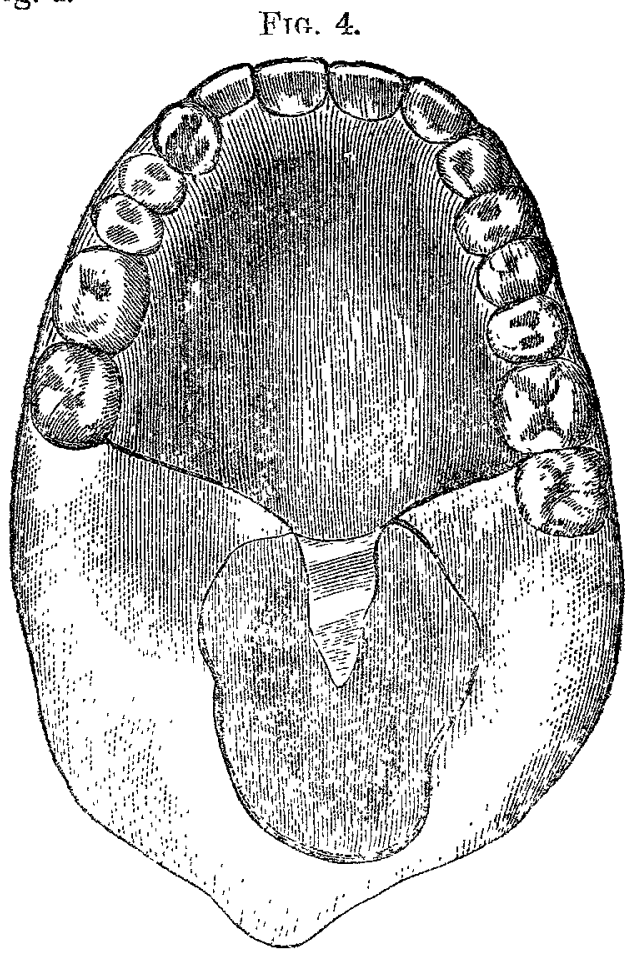

The result of the instrument being in its position was highly satisfactory to ourselves, as well as to the patient. The gap was kept perfectly closed, even when the muscles were subjected to strong action, and this without any chafing of the parts on which the plug pressed. Under these conditions, the symmetry of the mouth liaving been fairly restored, its natural functions returned. Degluticion, which had previously been both difficult and painful, from food passing the fissure and lodging above the palate, was now proceeded with in ordinary comfort; while articulation, instead of being very defective in tone, from sounds escaping through the posterior passages of the nares, in a short time resumed the character which belongs to perfect organs. Indeed, the delay in this particular arose more from the time which was racuired for the tongue to get adapted to the instrument than from any shortcomings in the instrument itself. 